\title{
Quantitative Genetics, Pleiotropy, and Morphological Integration in the Dentition of Papio hamadryas
}

\author{
Leslea J. Hlusko • Michael C. Mahaney
}

Received: 29 June 2008/ Accepted: 20 November 2008/Published online: 7 March 2009

(c) The Author(s) 2009. This article is published with open access at Springerlink.com

\begin{abstract}
Variation in the mammalian dentition is highly informative of adaptations and evolutionary relationships, and consequently has been the focus of considerable research. Much of the current research exploring the genetic underpinnings of dental variation can trace its roots to Olson and Miller's 1958 book Morphological Integration. These authors explored patterns of correlation in the postcanine dentitions of the owl monkey and Hyopsodus, an extinct condylarth from the Eocene. Their results were difficult to interpret, as was even noted by the authors, due to a lack of genetic information through which to view the patterns of correlation. Following in the spirit of Olson and Miller's research, we present a quantitative genetic analysis of dental variation in a pedigreed population of baboons. We identify patterns of genetic correlations that provide insight to the genetic architecture of the baboon dentition. This genetic architecture indicates the presence of at least three modules: an incisor module that is genetically independent of the post-canine dentition, and a premolar module that demonstrates incomplete pleiotropy with the molar module. We then compare this matrix of genetic correlations to matrices of phenotypic correlations between the same measurements made on museum specimens of another baboon subspecies and the Southeast Asian colobine Presbytis. We observe moderate significant correlations between the matrices from these three primate taxa. From
\end{abstract}

\section{J. Hlusko ( $\square)$}

Department of Integrative Biology, University of California, 3060 Valley Life Sciences Bldg, Berkeley 94720, CA, USA e-mail: hlusko@berkeley.edu

M. C. Mahaney

Department of Genetics, Southwest Foundation for Biomedical Research, Southwest National Primate Research Center, P. O. Box 760549, San Antonio 78245-0549, TX, USA these observations we infer similarity in modularity and hypothesize a common pattern of genetic integration across the dental arcade in the Cercopithecoidea.

Keywords Dental variation - Modularity - Evolution · Primates · Genetic architecture

\section{Introduction}

Fifty years ago Olson and Miller published Morphological Integration (1958), developing the intellectual foundation for much of the current research exploring the relationship between genotype and phenotype (Mitteroecker and Bookstein 2008). In honor of the fiftieth anniversary of Olson and Miller's seminar publication, we discuss their contributions to dental morphological evolution specifically and follow with our study of the genetic underpinnings of morphological integration in the primate dentition, a study inspired by the 1958 book.

Olson and Miller (1958) noted that "character changes occurring in evolution of species could not be considered to be independent of each other... the interrelationships of changing characters [is] a primary point of interest" (p. 1). They divided these interrelationships into $\rho$-groups and $\rho \mathrm{F}-$ groups, the former being correlations of a particular level, and the latter being correlations that result from a common function. The authors then provide several examples of how these correlations can elucidate morphological evolution.

The size and shape of the dentition is of fundamental importance in vertebrate evolution, as teeth are highly informative of an animal's diet, foraging strategy, interactions with conspecifics, and phylogenetic relationships. Additionally, teeth are primarily inorganic and thus survive 
well in the fossil record. For many vertebrates, all we know of them is what their teeth looked like.

Olson and Miller (1958) recognized the importance of the dentition in vertebrate evolution and consequently dedicated more than $20 \%$ of Morphological Integration to a discussion of $\rho$ - and $\rho$ F-groups within tooth size variation. They studied linear measurements for all post-canine teeth of Aotus trivirgatus (the small South American owl monkey) and the extinct condylarth Hyopsodus from the Eocene of North America. Despite the former being a primate and the latter a primitive ungulate (Gingerich 1974), they have similar dental morphologies.

Olson and Miller concluded that the post-canine dentition, as a whole, is poorly integrated, but that each tooth is highly integrated. They were also the first to note that these results were difficult to interpret, largely, they state, because there are no "guiding principles" for how to frame these results (1958, p. 182). They elaborate,

Evidence from studies of the genetics of dentition is virtually non-existant, and until the situation is remedied the uncertainties inherent in purely inferential interpretations cannot be removed. If, however, it is possible to gain additional insight into the scope of the selective unit, some progress can be made toward an understanding of the subordinate dental characters that are so important to studies of fossil mammals. Investigations directed toward this end fall within the domain of the concept of morphological integration. (1958, p. 182)

One of the most significant sources of genetic insight since 1958 has been developmental genetics. We have learned a considerable amount about the genes necessary to make a tooth, and how they interact during odontogenesis (reviewed in Jernvall and Thesleff 2000; Stock 2001; Tucker and Sharpe 2004). Our current understanding of tooth development is largely derived from gene expression and knock-out studies on mice. However, the few comparative analyses done to date demonstrate that the genetics of tooth organogenesis are likely to be highly conserved across mammals (e.g., Keränen et al. 1998; Kapadia et al. 2007; Lin et al. 2007; Miyado et al. 2007).

The next step towards achieving Olson and Miller's goal of identifying a "guiding principle" is to translate what is known about tooth developmental genetics to our understanding of how teeth vary within a population, and how this has evolved through time-connecting the genetics of organogenesis to population-level phenotypic variation (e.g., Nemeschkal 1999; Stern 2000; Hlusko 2004; Colosimo et al. 2005). This has become a productive research direction within biology (Koentges 2008), though by no means facile or straightforward (Weiss 2008).
The concept of modularity provides an essential tool for exploring the relationship between the genotype and phenotype, often referred to as genotype-phenotype mapping (Wagner 1996; Schlosser and Wagner 2004; Wagner et al. 2007). Modularity in the vertebrate limb is a successful example, primarily because of the patterned function and expression of Hox genes. Hox gene expression patterns have been demonstrated to correspond to morphological modularity within vertebrate autopods (Wagner and Vargas 2008), forelimbs (Reno et al. 2008), and entire limbs (Shubin et al. 1997; Shubin 2002).

However, Hox genes are not expressed in the first branchial arch from which the dentition derives (James et al. 2002), and therefore do not similarly pattern the dental arcade. Instead, the patterning of the dentition may be due to a combinatorial code of the Barx, Dlx, Msx, and Pitx gene families (Cobourne and Sharpe 2003). The applicability of this odontogenic combinatorial code model to non-mouse taxa, however, remains to be determined (for alternatives see Weiss et al. 1998; Stock 2001).

Another approach for identifying the genetic underpinnings of morphological integration is quantitative genetics. Lande (1979, 1980); Cheverud (1982, 1989, 1995, 1996a, b), Cheverud and colleagues (e.g., Cheverud et al. 1983; Marroig et al. 2004), and numerous others (e.g., Schluter 2000) have demonstrated the power of quantitative genetics for identifying shared genetic effects between traits (e.g., pleiotropy), and understanding how these genetic correlations can affect morphological evolution.

Quantitative genetic analyses test the hypothesis that environmental, or non-genetic factors alone can account for the phenotypic similarities seen among family members. A significant heritability estimate for one phenotype, or a genetic correlation between two phenotypes, indicates that environmental effects by themselves cannot account for the pattern of phenotypic variation seen in a population of related individuals, and as such, the degrees of interrelatedness contribute to the phenotypic similarities (i.e., genes shared due to a common ancestor, estimated via the kinship coefficient).

We employed this method to identify the genetic underpinnings of morphological integration by determining how much of a phenotypic correlation between two phenotypes results from the genetic correlation between them. In other words, we explore Olson and Miller's (1958) $\rho$-groups as genetic correlation groups-this is now most commonly presented in matrix form.

Phenotypic variation $(\mathrm{Vp})$ is the sum of the genetic $(\mathrm{Vg})$ and environmental variances $(\mathrm{Ve})$, such that $\mathrm{Vp}=$ $\mathrm{Vg}+\mathrm{Ve}$. Therefore, it is evident that the higher the heritabilities of the phenotypes included in a matrix (i.e., the greater the proportion of the phenotypic variance that is due to the additive effects of genes), the more the 
phenotypic correlation matrix, $\mathrm{P}$, will reflect the genetic correlation matrix, G (e.g., Cheverud 1988). Numerous studies have demonstrated this phenomenon, that phenotypic correlation matrices reflect the underlying genetic correlations (e.g., Cheverud 1988; Arnold 1992; Roff 1995, 1996; Koots and Gibson 1996).

The gold standard for evolutionary quantitative genetic analyses is to estimate genetic correlations for phenotypes in all populations studies (e.g., Arnold and Phillips 1999; Phillips and Arnold 1999; Steppan et al. 2002; Caruso et al. 2005; Colosimo et al. 2005), and ultimately tie these to gene expression studies (e.g., Nemeschkal 1999). But given the difficulty of establishing pedigree structure, this is not possible for most populations or species, especially those that are extinct. However, a number of other researchers have demonstrated that cautiously exploring the phenotypic correlation matrix as a proxy for the genetic correlation matrix of a population is a productive means through which to study the evolution of modularity, or morphological integration as Olson and Miller predicted in 1958 (e.g., Cheverud et al. 1989; Ackermann and Cheverud 2000, 2002; Mezey et al. 2000; Magwene 2001).

Within primates, this type of research has largely focused on the cranium (e.g., Richtsmeier et al. 1984; Kohn et al. 1993; Cheverud 1996b; Ackermann and Cheverud 2002; Marroig et al. 2004; Roseman 2004; Marroig and Cheverud 2005; Wolf et al. 2005; Ackermann 2007; Mitteroecker and Bookstein 2008; Sherwood et al. 2008), all identifying morphological integration in the cranium, and demonstrating that cranial evolution follows predictable trajectories described by the pattern of genetic correlations (e.g., Marroig and Cheverud 2005).

Although the application of quantitative genetic methods to primate dental variation is not new, the majority of published studies have analyzed data from humans (reviewed in Rizk et al. 2008). We have undertaken the most extensive quantitative genetic analysis of dental variation in a non-human primate to date, employing a captive pedigreed breeding colony of baboons housed at the Southwest National Primate Research Center (Hlusko 2004; Hlusko et al. 2002, 2004a, b, 2006; Hlusko and Mahaney 2003, 2007a, b, 2008).

Here we report on a quantitative genetic analysis of maxillary tooth size variation in this pedigreed population of baboons. These analyses reveal, for the first time, the genetic architecture of population level tooth size variation in Papio hamadryas. Patterns of high genetic correlations are hypothesized to underlie modularity in tooth size variation across the dental arcade. Given the highly conserved nature of most of dental developmental genetics noted above, these modules may be present in other baboons, other Old World Monkeys (OWM), primates more broadly, and possibly even other mammals.
In order to test the hypothesis of common modularity, we undertake a series of matrix comparisons. First, we compare the matrix of genetic correlations to the matrix of phenotypic correlations within the same pedigreed population to determine the degree to which the latter reflect the former in these baboons. We then compare the genetic correlation matrix to the phenotypic correlation matrices for non-related baboons and the more evolutionarily distant Southeast Asian colobine Presbytis to assess the degree to which the genetic underpinnings of odontometric modularity detected in the captive baboons might also be detected in other cercopithecoids.

\section{Materials}

Data for the genetic analyses were collected from a large captive, pedigreed breeding colony of baboons $(>3000)$ housed at the Southwest National Primate Research Center (SNPRC) at the Southwest Foundation for Biomedical Research in San Antonio, Texas. This colony is comprised largely of Papio hamdryas anubis with some $P$. h. cynocephalus, and P. h. hamadryas (as defined in Jolly 1993).

The colony is maintained in pedigrees with all mating opportunities controlled. Genetic management of the colony was started over 20 years ago and allows for data collection from non-inbred animals. All non-founder animals in this study resulted from matings that were random with respect to dental, skeletal, and developmental phenotype. The female to male sex ratio is approximately $2: 1$. Genetic marker maps were made for 694 individuals (Rogers et al. 2000), making QTL analyses for these data possible (in preparation).

All pedigree data management and preparation was facilitated through use of the computer package PEDSYS (Dyke 1996). The animals from which data have been collected $(n=630)$ are distributed across 11 extended pedigrees that are 3-5 generations deep. The mean number of animals with data per pedigree is 44 ; these individuals typically occupy the lower 2-3 generations.

All SNPRC odontometric data were collected from high resolution plaster dental casts made from living animals while they were anesthetized (for details see Hlusko et al. 2002) or from skeletal remains curated at the University of Washington under the direction of J. Cheverud. The Institutional and Animal Care and Use Committee, in accordance with the established guidelines (National Research Council 1996), approved all procedures related to the treatment of the baboons during the conduct of this study. The dental data were collected either with calipers (incisors and premolars) or from digital photographs (molars) of the casts (protocol described in detail elsewhere, Hlusko et al. 2002). 
Phenotypic data consisted of standard linear size measurements of the maxillary dentition: mesiodistal length and labiolingual width for incisors, mesiodistal length and buccolingual width for premolars, mesiodistal length and mesial and distal buccolingual width for the molars. Measurements were not available for the canines as the canines are clipped or pulled for the animals' safety in captivity.

Phenotypic data for the non-pedigreed populations are from the National Science Foundation-sponsored on-line free access database of Old World Monkey dental metrics, PRIMO (http://www.nycep.org/primo/). We used two samples from this database. The first consists of 186 Papio hamadryas (34 categorized as $P$. h. anubis and 152 as $P$. $h$. ursius). The second sample is a smaller collection of Presbytis $(n=25)$. These specimens are all housed in museum collections (American Museum of Natural History, British Museum of Natural History, Florida State Museum, National Museum of Natural History, Senckenbergische Anatomie, and C. Jolly's collection). The same maxillary linear measurements were used for the SNPRC and the PRIMO samples; all PRIMO data were collected with calipers. Figure 1 shows a typical baboon dentition.

\section{Analytical Methods}

Statistical genetic analyses were conducted by means of a maximum likelihood based variance decomposition approach implemented in the computer package SOLAR (Almasy and Blangero 1998). The phenotypic covariance for each trait within a pedigree is modeled as $\Omega=2 \Phi \sigma_{\mathrm{G}}^{2}+I \sigma_{\mathrm{E}}^{2}$, where $\Phi$ is a matrix of kinship coefficients for all relative pairs in a pedigree, $\sigma_{\mathrm{G}}^{2}$ is the additive genetic variance, $I$ is an identity matrix (composed of ones along the diagonal and zeros for all off-diagonal elements), and $\sigma_{\mathrm{E}}^{2}$ is the environmental variance. The components of the phenotypic variance are additive, such that $\sigma_{\mathrm{P}}^{2}=\sigma_{\mathrm{G}}^{2}+\sigma_{\mathrm{E}}^{2}$, enabling us to estimate heritability, or the proportion of the phenotypic variance attributable to additive genetic effects as $h^{2}=\frac{\sigma_{\mathrm{G}}^{2}}{\sigma_{\mathrm{P}}^{2}}$. Phenotypic variance attributable to non-genetic factors is estimated as $e^{2}=1-h^{2}$. The mean effects of sex and age were tested in the analyses and included in all subsequent analyses if found to significantly contribute to the phenotypic variance of a trait.

Using extensions to univariate genetic analyses that encompass the multivariate state (Hopper and Mathews 1982; Lange and Boehnke 1983; Boehnke et al. 1987), we modeled the multivariate phenotype of an individual as a linear function of the measurements on the individual's traits, the means of these traits in the populations, the covariates and their regression coefficients, plus the additive genetic values and random environmental deviations (described in detail in Mahaney et al. 1995).
From this model, we obtained the phenotypic variancecovariance matrix from which we partitioned the additive genetic and random environmental variance-covariance matrices, given the relationships (kinship coefficients) observed in the pedigree. From these two variancecovariance matrices, we estimated the additive genetic correlation, $\rho_{\mathrm{G}}$, and the environmental correlation, $\rho_{\mathrm{E}}$, between trait pairs. Respectively, these correlations are estimates of the additive effects of shared genes (i.e., pleiotropy) and shared environmental (i.e., unmeasured and nongenetic) factors on the variance in a trait.

We use the maximum likelihood estimates of the additive genetic and environmental correlations to obtain the total phenotypic correlation between two traits, $\rho_{\mathrm{P}}$, as $\rho_{\mathrm{P}}=\sqrt{h_{1}^{2}} \sqrt{h_{2}^{2}} \rho_{\mathrm{G}}+\sqrt{\left(1-h_{1}^{2}\right)} \sqrt{\left(1-h_{2}^{2}\right)} \rho_{\mathrm{E}}$. The genetic correlation between trait pairs was estimated using multivariate extensions to the basic variance decomposition methods implemented in SOLAR (Almasy and Blangero 1998).

Significance of the maximum likelihood estimates for these parameters was assessed by means of likelihood ratio tests. Twice the difference of the maximum likelihoods of a general model (in which all parameters are estimated) and a restricted model (in which the value of a parameter to be tested is held constant at some value, usually zero) are compared. This difference is distributed asymptotically approximately as either a $1 / 2: 1 / 2$ mixture of $\chi^{2}$ and a point mass at zero for tests of parameters like $h^{2}$ for which a value of zero in a restricted model is at a boundary of the parameter space, or as a $\chi^{2}$ variate for tests of covariates for which zero is not a boundary value (Hopper and Mathews 1982). In both cases degrees of freedom is equal to the difference in the number of estimated parameters in the two models (Boehnke et al. 1987). However, in tests of parameters like $h^{2}$, whose value may be fixed at a boundary of their parameter space in the null model, the appropriate significance level is obtained by halving the $P$-value (Boehnke et al. 1987).

For bivariate models in which genetic correlations are found to be significantly greater than zero, additional tests are performed to compare the likelihood of a model in which the value of the genetic correlation is fixed at 1 or 0 to that of the unrestricted model in which the value of the genetic correlation is estimated. A significant difference between the likelihoods of the restricted and polygenic models suggests incomplete pleiotropy, i.e., not all of the additive genetic variance in the two traits is due to the effects of the same gene or genes.

Genetic correlations between traits can result from either pleiotropy or gametic phase disequilibrium (Lynch and Walsh 1998). The degree of gametic phase disequilibrium (or linkage disequilibrium, LD) is a function of a population's genetic history and demography: e.g., it will be lower in outbred populations with many unrelated founders 
as recombination exerts its affects each generation, higher in populations undergoing rapid expansion from a small number of founders and those resulting from recent admixture. Given a conducive set of population characteristics, the likelihood of genetic correlation between two traits being due to LD is higher for simple traits, with monogenic (or nearly so) inheritance. However, if variation in a pair of traits is attributable to the effects of multiple alleles at multiple loci, LD is not likely to be a major contributor to the genetic correlation (Lande 1980; Lynch and Walsh 1998). Therefore, we are cautiously confident that significant additive genetic correlations estimated in our analyses on pairs of complex, multifactorial dental measures from our non-inbred, extended baboon pedigrees are primarily indicative of pleiotropy rather than LD. Ongoing and planned whole genome screens and LD analyses in this population will help confirm this.

Genetic correlations between all possible pair-wise comparisons of the SNPRC dental linear metrics were used to construct a G matrix. We then calculated the elements of the $\mathrm{P}$ matrix for this sample of related individuals using the identity presented above. To assess the degree of similarity between the $\mathrm{G}$ and $\mathrm{P}$ correlation matrices for this pedigreed population, and between these matrices and the phenotypic (Pearson's) correlation matrices constructed for the PRIMO data, we employed the Mantel test (Mantel 1967; Cheverud 1989), implemented in the statistical software packer $\mathrm{R}^{\odot}$ (http://www.r-project.org/).

The Mantel test is a statistical test of correlation between two or more dissimilarity (e.g., distance) or similarity (correlation) matrices of equal rank. We assessed the significance of correlations estimated by this method empirically from this distribution of correlations obtained after permuting the rows and columns of the matrices 1000 times. This procedure reduces our reliance on assumptions concerning the statistical distributions underlying the two matrixes and mitigates the effects of nonindependence of elements within the matrices.

\section{Results}

Heritability estimates for the SNPRC population are reported in Table 1. All maxillary tooth linear measurements are heritable $(P \leq 0.05)$ except for the mesiodistal length of the left third molar, probably the result of the relatively small sample $(n=234)$.

Additive genetic correlations for all possible pair-wise comparisons are presented in Appendix. Figure 2 is a visual composite of the right and left side results. The only phenotype pairing that did not yield a significant result on either side of the dental arcade is the width of the third premolar and the distal width of the third molar.
We found that 4 of 6 incisor:incisor correlations are significantly different from zero, with three $\rho_{\mathrm{G}}>0.80$. Only five of the 52 possible incisor:post-canine $\rho_{\mathrm{G}}$ estimates are significantly different from zero and all but one of these is below 0.50. All possible premolar:premolar $\rho_{\mathrm{G}}$ estimates are significantly different from zero; three are not significantly different from one. Eleven of the 36 premolar:molar analyses returned genetic correlations that are not statistically different from zero; the rest $(67 \%)$ indicate significant shared genetic effects. Only 6 of the molar: molar correlations are not statistically different from zero.

A visual inspection of the SNPRC P and G matrices (Fig. 2) reveals a similar overall pattern. Mantel's similarity test yields $r=0.873$ for the left $\mathrm{P}$ versus $\mathrm{G}$ matrices and $r=0.717$ for the right $\mathrm{P}$ versus $\mathrm{G}$ matrices $(P<0.001)$ (for comparison, SNPRC left versus right $\mathrm{P}$ matrices returned an estimate of $r=0.795, P<0.001$ ). These matrices are also statistically similar to the PRIMO Papio P matrix (SNPRC G matrix, $r=0.36, P<0.001$; SNPRC P matrix, $r=0.35, P=0.004)$. The SNPRC and PRIMO Papio matrices are also statistically similar to the PRIMO Presbytis P matrix (SNPRC G matrix, $r=0.474$, $P<0.001$; SNPRC P matrix, $r=0.436, P=0.005$ (right) and $r=0.5792, P<0.001$ (left); PRIMO Papio matrix, $r=0.346, P=0.016$ ).

\section{Discussion}

Two fundamental questions in biology concern the relationship between genes and anatomy. How does the genotype effect the phenotype and how has this relationship influenced morphological evolution as seen through the fossil record? We are currently pursuing these two research questions using the baboon dentition as a model system. The results presented here are part of this larger project.

We have undertaken a quantitative genetic analysis of dental variation in the SNPRC baboon population to establish the genetic architecture of dental variation. We find that the G and P matrices of SNPRC dental size variation correlations are significantly similar with a relatively high $r$ value $(r=0.639 ; P<0.001)$. This estimate is on the higher end of $r$ values reported for comparisons of $\mathrm{G}$ and $\mathrm{P}$ correlation matrices (Table 1, Cheverud 1988), indicating that the $G$ matrix is highly predictive of the $P$ matrix, as was expected and as has been reported for other populations (e.g., Cheverud 1988, 1995; Arnold 1992; Roff 1995, 1996; Koots and Gibson 1996).

The results of our comparisons of the odontometric phenotypic correlation matrices for these three cercopithecoid species represent the first step towards determining whether or not this genetic architecture is characteristic of 
Table 1 Polygenic models for individual tooth measurements ${ }^{\mathrm{a}}$

\begin{tabular}{|c|c|c|c|c|c|c|c|c|c|}
\hline Trait & Mean & Var & $n$ & Kurtosis & $P$-value & Total $h^{2}$ & Total $c^{2}$ & Total $e^{2}$ & Residual $h^{2} \pm \mathrm{SE}$ \\
\hline \multicolumn{10}{|c|}{ Baboon right maxillary } \\
\hline I111 & 9.07 & 1.08 & 473 & -0.3274 & $<0.0001$ & 0.49 & 0.194 & 0.32 & $0.605 \pm 0.12$ \\
\hline I1md & 9.51 & 0.55 & 480 & 0.4816 & $<0.0001$ & 0.51 & 0.125 & 0.37 & $0.578 \pm 0.11$ \\
\hline I211 & 7.98 & 1.09 & 463 & 0.5029 & $<0.0001$ & 0.51 & 0.204 & 0.28 & $0.642 \pm 0.11$ \\
\hline $\mathrm{I} 2 \mathrm{md}$ & 7.05 & 0.91 & 474 & 0.5982 & $<0.0001$ & 0.52 & 0.141 & 0.33 & $0.611 \pm 0.11$ \\
\hline P31 & 6.71 & 0.31 & 276 & -0.1182 & 0.006 & 0.25 & 0.201 & 0.55 & $0.316 \pm 0.15$ \\
\hline $\mathrm{P} 3 \mathrm{w}^{*}$ & 7.82 & 0.44 & 317 & 0.7641 & $<0.0001$ & 0.43 & 0.346 & 0.22 & $0.659 \pm 0.20$ \\
\hline P4l & 7.63 & 0.27 & 400 & 0.4849 & $<0.0001$ & 0.48 & 0.295 & 0.23 & $0.680 \pm 0.12$ \\
\hline $\mathrm{P} 4 \mathrm{w}^{*}$ & 8.51 & 0.38 & 430 & 0.0152 & $<0.0001$ & 0.37 & 0.368 & 0.26 & $0.591 \pm 0.12$ \\
\hline M11* & 10.68 & 0.40 & 471 & 0.2626 & $<0.0001$ & 0.44 & 0.336 & 0.23 & $0.659 \pm 0.11$ \\
\hline M1mw & 8.38 & 0.30 & 438 & 0.7627 & $<0.0001$ & 0.55 & 0.184 & 0.27 & $0.672 \pm 0.14$ \\
\hline M1dw* & 7.87 & 0.29 & 439 & 0.4530 & $<0.0001$ & 0.62 & 0.190 & 0.19 & $0.763 \pm 0.16$ \\
\hline M21* & 12.47 & 0.69 & 531 & 1.4037 & $<0.0001$ & 0.46 & 0.425 & 0.12 & $0.798 \pm 0.11$ \\
\hline M2mw* & 9.88 & 0.47 & 530 & 0.5056 & $<0.0001$ & 0.39 & 0.291 & 0.32 & $0.544 \pm 0.12$ \\
\hline M2dw & 8.85 & 0.40 & 517 & 0.5223 & $<0.0001$ & 0.37 & 0.305 & 0.32 & $0.533 \pm 0.13$ \\
\hline M31* & 12.62 & 0.83 & 183 & 0.0403 & 0.013 & 0.24 & 0.483 & 0.28 & $0.455 \pm 0.26$ \\
\hline M3mw* & 9.97 & 0.75 & 444 & 0.9430 & $<0.0001$ & 0.35 & 0.381 & 0.27 & $0.562 \pm 0.13$ \\
\hline M3dw & 8.50 & 0.56 & 286 & 0.0408 & 0.021 & 0.22 & 0.345 & 0.44 & $0.331 \pm 0.19$ \\
\hline \multicolumn{10}{|c|}{ Baboon left maxillary } \\
\hline I111 & 8.96 & 1.06 & 469 & 0.5843 & $<0.0001$ & 0.37 & 0.176 & 0.46 & $0.446 \pm 0.11$ \\
\hline I1md & 9.58 & 0.48 & 471 & 0.0452 & $<0.0001$ & 0.55 & 0.156 & 0.29 & $0.654 \pm 0.10$ \\
\hline $\mathrm{I} 211 *$ & 7.12 & 0.60 & 481 & 0.3304 & $<0.0001$ & 0.54 & 0.099 & 0.36 & $0.595 \pm 0.12$ \\
\hline $\mathrm{I} 2 \mathrm{md}$ & 5.62 & 0.48 & 471 & 0.3270 & $<0.0001$ & 0.36 & 0.212 & 0.43 & $0.452 \pm 0.11$ \\
\hline $\mathrm{P} 31^{*}$ & 6.69 & 0.34 & 287 & -0.1619 & 0.017 & 0.20 & 0.148 & 0.65 & $0.236 \pm 0.14$ \\
\hline $\mathrm{P} 3 \mathrm{w}$ & 7.75 & 0.41 & 323 & 0.5493 & 0.004 & 0.18 & 0.388 & 0.43 & $0.292 \pm 0.14$ \\
\hline $\mathrm{P} 41^{*}$ & 7.65 & 0.28 & 418 & 0.5649 & $<0.0001$ & 0.34 & 0.285 & 0.37 & $0.478 \pm 0.10$ \\
\hline $\mathrm{P} 4 \mathrm{w}^{*}$ & 8.52 & 0.37 & 454 & -0.0675 & $<0.0001$ & 0.42 & 0.303 & 0.27 & $0.608 \pm 0.12$ \\
\hline M11* & 10.66 & 0.37 & 470 & -0.1161 & $<0.0001$ & 0.47 & 0.379 & 0.15 & $0.751 \pm 0.12$ \\
\hline M1mw & 8.38 & 0.30 & 458 & 0.5261 & $<0.0001$ & 0.56 & 0.221 & 0.22 & $0.722 \pm 0.11$ \\
\hline M1dw & 7.89 & 0.27 & 454 & 0.3962 & $<0.0001$ & 0.62 & 0.206 & 0.17 & $0.786 \pm 0.12$ \\
\hline M21 & 12.55 & 0.69 & 539 & 0.6799 & $<0.0001$ & 0.44 & 0.479 & 0.08 & $0.847 \pm 0.10$ \\
\hline $\mathrm{M} 2 \mathrm{mw}$ & 9.90 & 0.45 & 539 & 0.7125 & $<0.0001$ & 0.49 & 0.276 & 0.23 & $0.676 \pm 0.11$ \\
\hline M2dw* & 8.92 & 0.39 & 530 & 0.2218 & $<0.0001$ & 0.39 & 0.302 & 0.31 & $0.557 \pm 0.11$ \\
\hline M31* & 12.49 & 0.87 & 234 & 0.8855 & 0.07 & 0.13 & 0.432 & 0.44 & $0.231 \pm 0.19$ \\
\hline M3mw* & 9.98 & 0.61 & 440 & 0.3233 & 0.002 & 0.15 & 0.373 & 0.48 & $0.234 \pm 0.11$ \\
\hline
\end{tabular}

${ }^{a}$ Total $c^{2}=$ amount of phenotypic variance attributable to covariates. Total $h^{2}=\left(\right.$ Residual $\left.h^{2}\right)\left(1-\right.$ Total $\left.c^{2}\right)$. Total $e^{2}=[1-($ Total $c^{2}+$ Total $\left.h^{2}\right)$ ]; * values were I-normalized to reduce kurtosis. Kurtosis values reported are for the i-normalized trait. All data are presented in $\mathrm{mm}$ but were analyzed as multiples of 10 to raise the variance above 1.0

other Old World Monkeys, extant and extinct (using the fossil record of OWM evolution in Africa). The phenotypic correlation matrices required for these analyses require large sample sizes, which are still being acquired. However, we were able to use already-collected data from the PRIMO database to undertake some preliminary analyses.

The Papio hamadryas ursinus/anubis and Presbytis $\mathrm{P}$ matrices are significantly similar to the SNPRC G matrix although the $r$ estimates are not high $(\sim 0.35)$ compared to the SNRPC P and G matrix comparison. While we find it intriguing that these matrices do show statistically significant similarity, we are cautious in the biological interpretation of these results, given that the $r$ values are low. Further analyses, larger sample sizes, and more control over data collection methods (these data were not collected by the authors and followed different protocols) are needed to adequately test the hypothesis that the structure of the G matrix estimated for the SNPRC population is characteristic of the P matrices of other Old World Monkeys. 


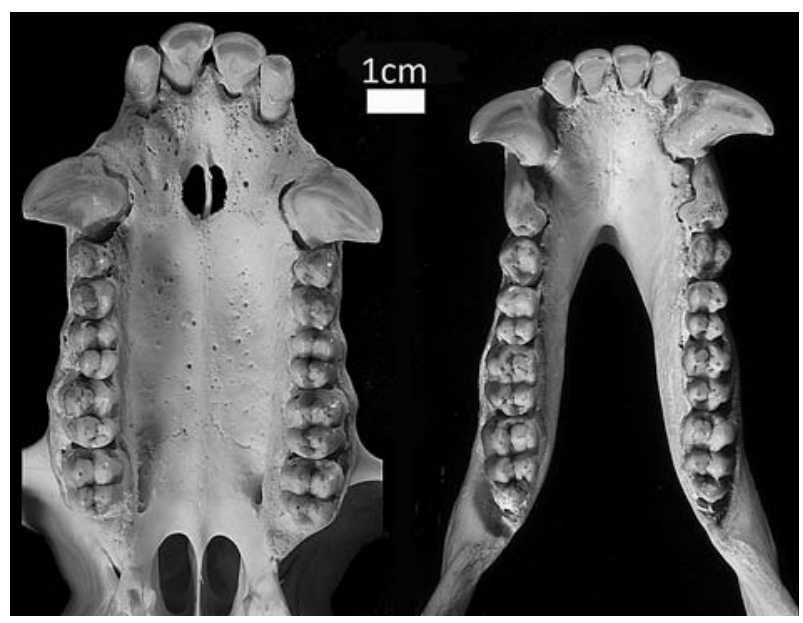

Fig. 1 Occlusal view of the Papio hamadryas maxillary (left) and mandibular (right) dental arcades

With that caveat in mind, we propose the hypothesis that these initial results reveal genetic modularity within dental variation of Old World Monkeys, and perhaps of primates and mammals more generally. While speculative at this point, there is evidence from the developmental side that bolsters this interpretation.

At the end of the 19th century, Bateson $(1892,1894)$ compared the variation of serially homologous structures to Chladni figures, frequency interference in wave patterns. Butler $(1939,1956)$ adapted this concept to the dentition and proposed that classes of teeth derive from one 'type,' proposing that tooth shape variation results from identical tooth primordia reacting to different concentrations of morphogens. This is known as the field theory and is characterized by ultimate tooth shape being determined by extrinsic factors expressed within three separate fields (incisor, canine, post-canine).

An alternative is the clone theory, proposed by Osborn (1978). In this hypothesis, each tooth in a class is produced by the replication of the original type or polar tooth (i.e., the first molar for the molar field). Morphology is therefore predetermined by intrinsic factors.

The concept of dental fields has been explored primarily through analyses of phenotypic correlation (e.g., Dahlberg 1945; Van Valen 1961; Henderson and Greene 1975; Lombardi 1975). However, none of these phenotypic correlation analyses is particularly conclusive and can be argued to support both theories. The resolution between the clone and the field theories for explaining dental patterning has been hindered by the same lack of genetic information that complicated Olson and Miller's (1958) interpretations.

The field and clone models described above, and the odontogenic combinatorial code outlined in the introduction, all propose various levels of modularity within the dentition. With that in mind, it is not surprising that we find modularity in our quantitative genetic analysis. The genetic architecture of the SNPRC baboon maxillary dentition provides evidence for at least three modules that affect tooth size variation: incisors, premolar, and molar. The incisor module is genetically independent of the entire post-canine dentition, whereas the premolar and molar modules have overlapping genetic effects.

While the three developmental models outline above are distinct from each other to various degrees, our results accord with elements of each. For example, the odontogenic combinatorial code proposed for patterning the mouse dentition (Cobourne and Sharpe 2003), if found to be common to all mammals, would suggest at least two modules within the dentition: an incisor and a molar module. Our analyses demonstrate significant genetic independence between the incisors and molars, supporting Cobourne and Sharpe's hypothesis. The odontogenic code does not address premolars, as mice lack premolars and canines.

Under the clone model, where factors intrinsic to each tooth primordium determine tooth size and shape, we would hypothesize that modules do not covary. The genetic independence we found between incisors and molars also supports this model. Additionally, the lack of a genetic correlation between premolars and incisors in the SNPRC baboons accords with this prediction.

However, we find that premolar size variation does have overlapping but non-identical genetic effects with molar size variation. Additional research is needed to explore this in more detail, but this result does accord with the field theory, as extrinsic factors influencing tooth size along the post-canine dentition could result in incomplete pleiotropy. Data from developmental genetics also supports applying elements of the field theory to our understanding of how premolars and molars are genetically interrelated (e.g., Kassai et al. 2005; Salazar-Ciudad and Jernvall 2002), as does a phenotypic analysis of seal tooth shape (Jernvall 2000).

After 50 years, Olson and Miller's predictions are now being realized. Genotype-phenotype mapping provides a useful framework for understanding morphological evolution. Here specifically, we have shown that a quantitative genetic analysis of tooth size variation may well provide insight, or a "guiding principle" for how to identify and conceptualize morphological integration within the dentition of primates, and possibly mammals more broadly.

We hope to track the evolution of these genetic modules through time by exploring the $\mathrm{P}$ matrices of various taxa within the Old World Monkey fossil record. Ultimately, we may be able to reconstruct the phenogenetic evolution (Weiss 2005) of the primate dentition by revealing how the genotype has responded to selective pressures placed on the phenotype, by correlating phenogenetic changes with 
Fig. 2 Genetic and phenotypic correlation matrices.

Correlations were estimated as described in the text. The

SNPRC genetic correlation matrix is a composite of the left and right sides of the maxillary dental arcade. The SNPRC phenotypic correlation matrix shows the average between the left and right side estimates

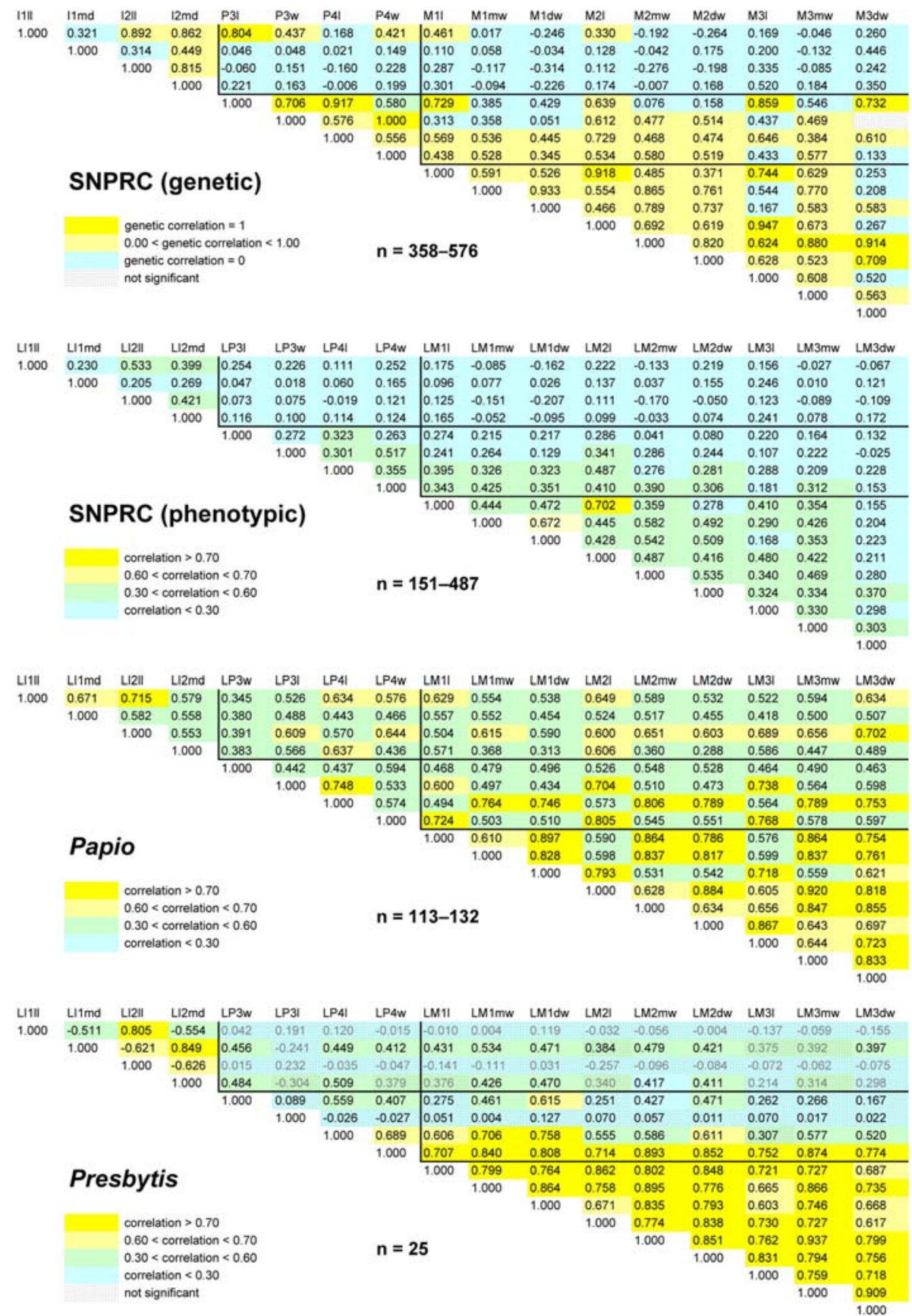

\section{Presbytis}

correlation $>0.70$ $0.60<$ correlation $<0.70$ $0.30<$ correlation $<0.60$ correlation $<0.30$ not significant

\begin{tabular}{llllllllll}
1.000 & 0.707 & 0.840 & 0.808 & 0.714 & 0.893 & 0.852 & 0.752 & 0.874 & 0.774 \\
\hline 1.000 & 0.799 & 0.764 & 0.862 & 0.802 & 0.848 & 0.721 & 0.727 & 0.687 \\
& 1.000 & 0.864 & 0.758 & 0.895 & 0.776 & 0.665 & 0.866 & 0.735 \\
& & 1.000 & 0.671 & 0.835 & 0.793 & 0.603 & 0.746 & 0.668 \\
& & & 1.000 & 0.774 & 0.838 & 0.730 & 0.727 & 0.617 \\
$\mathbf{n = 2 5}$ & & & & 1.000 & 0.851 & 0.762 & 0.937 & 0.799 \\
& & & & & 1.000 & 0.831 & 0.794 & 0.756 \\
& & & & & & 1.000 & 0.759 & 0.718 \\
& & & & & & & 1.000 & 0.909 \\
& & & & & & & & & \\
& & & & & & & & &
\end{tabular}


the University of California Berkeley who have helped with data collection: C. Anderson, L. Bates, L. Broughton, L. Buchanan, T. Cannistraro, S. Deldar, N. Do, Z. Fletcher, J. Hernandez, L. Holder, J. Irwin, T. Koh, A. Liberatore, M.-L. Maas, C. Page, D. Pillie, N. Reeder, N. Wu, A. Yen, E. Young, and A. Zowghi. We also thank Eric Delson and colleagues for making their data available via the PRIMO on-line database. This material is based upon work supported by the National Science Foundation under Grants Nos. BCS-0500179, BCS-0130277, and BCS-0616308. The University of Illinois, UrbanaChampaign's Research Board also helped fund this research. NIH/ NCRR P51 RR013986 supports the Southwest National Primate Research Center.

Open Access This article is distributed under the terms of the Creative Commons Attribution Noncommercial License which permits any noncommercial use, distribution, and reproduction in any medium, provided the original author(s) and source are credited.

\section{Appendix}

Table 2 Bivariate statistical genetic analyses: Maximum-likelihood estimates of genetic and environmental correlations ${ }^{\mathrm{a}}$

\begin{tabular}{|c|c|c|c|c|c|}
\hline \multirow[t]{2}{*}{ Phenotype pair } & \multirow[t]{2}{*}{$\mathrm{N}$} & \multicolumn{2}{|c|}{$\begin{array}{l}\text { Correlations } \\
\text { (MLEs) }\end{array}$} & \multicolumn{2}{|c|}{$\begin{array}{l}\text { Significance of } \\
\text { correlations } \\
P(\text { Hypothesis })\end{array}$} \\
\hline & & $\rho_{\mathrm{G}}$ & $\rho_{\mathrm{E}}$ & $\rho_{C}=0$ & $\left|\rho_{\mathrm{G}}\right|=1$ \\
\hline \multicolumn{6}{|c|}{ Baboon right maxillary } \\
\hline I11l v I1md & 481 & 0.322 & 0.269 & 0.055 & $<0.0000001$ \\
\hline I11l v I21l & 492 & 0.893 & 0.215 & $<0.0001$ & 0.003 \\
\hline I11l v I2md & 492 & 0.863 & -0.236 & $<0.0001$ & 0.005 \\
\hline I11l v P31 & 529 & 0.804 & -0.246 & 0.008 & 0.28 \\
\hline [11l v P3w & 542 & 0.437 & 0.004 & 0.039 & 0.0008 \\
\hline 111 v P41 & 564 & 0.168 & 0.353 & 0.277 & $<0.0000001$ \\
\hline 111 v P4w & 563 & 0.421 & -0.012 & 0.012 & $<0.00001$ \\
\hline 111 v M11 & 548 & 0.461 & -0.039 & 0.002 & $<0.0000001$ \\
\hline 111 v M1mw & 543 & 0.017 & -0.195 & 0.926 & $<0.0000001$ \\
\hline I11l v M1dw & 543 & -0.246 & 0.086 & 175 & 0.0000001 \\
\hline [11l v M21 & 575 & 0.330 & 0.159 & 0.030 & $<0.0000001$ \\
\hline I11l v M2mw & 576 & -0.192 & 0.0125 & 0.200 & 0.0000001 \\
\hline 1111 v MLddw & 572 & -0.265 & 0.117 & S & 0.000002 \\
\hline I111 v M31 & 531 & 0.169 & 0.598 & 0.040 & 0.018 \\
\hline I11l v M3mw & 564 & -0.046 & 0.196 & 0.821 & $<0.0000001$ \\
\hline I11l v M3dw & 549 & -0.164 & 0.080 & 0.340 & 0.049 \\
\hline I1md v I2ll & 492 & 0.314 & -0.160 & 0.050 & $<0.0000001$ \\
\hline I1md v I2md & 492 & 0.450 & 0.022 & 0.006 & 0.0000001 \\
\hline I1md v P31 & 536 & 0.046 & 0.294 & 0.865 & 0.012 \\
\hline I1md v P3w & 545 & 0.048 & 0.345 & 0.801 & 0.00007 \\
\hline I1md v P4l & 566 & 0.021 & 0.295 & 0.901 & $<0.0000001$ \\
\hline I1md v P4w & 565 & 0.149 & 0.260 & 0.404 & $<0.0000001$ \\
\hline I1md v M11 & 552 & 0.112 & 0.398 & 0.483 & $<0.0000001$ \\
\hline I1md v M1mw & 547 & 0.059 & 0.295 & 0.752 & $<0.0000001$ \\
\hline I1md v M1dw & 547 & -0.034 & 0.284 & 0.851 & 0.0000001 \\
\hline I1md v M21 & 576 & 0.129 & 0.399 & 0.399 & $<0.0000001$ \\
\hline
\end{tabular}

Table 2 Appendix continued

\begin{tabular}{|c|c|c|c|c|c|}
\hline \multirow[t]{2}{*}{ Phenotype pair } & \multirow[t]{2}{*}{$\mathrm{N}$} & \multicolumn{2}{|c|}{$\begin{array}{l}\text { Correlations } \\
\text { (MLEs) }\end{array}$} & \multicolumn{2}{|c|}{$\begin{array}{l}\text { Significance of } \\
\text { correlations } \\
P \text { (Hypothesis })\end{array}$} \\
\hline & & $\rho_{\mathrm{G}}$ & $\rho_{\mathrm{E}}$ & $\rho_{\mathrm{G}}=0$ & $\left|\rho_{\mathrm{G}}\right|=1$ \\
\hline I1md v M2mw & 577 & -0.042 & 0.274 & 0.813 & $<0.0000001$ \\
\hline I1md v M2dw & 573 & 0.175 & 0.089 & 0.342 & 0.0000004 \\
\hline I1md v M31 & 535 & 0.200 & 0.489 & 0.422 & 0.021 \\
\hline I1md v M3mw & 567 & -0.132 & 0.251 & 0.485 & 0.0000009 \\
\hline I1md v M3dw & 553 & 0.125 & 0.070 & 0.642 & 0.061 \\
\hline $\mathrm{I} 211 \mathrm{v} \mathrm{I} 2 \mathrm{md}$ & 475 & 0.816 & -0.144 & $<0.0001$ & 0.0001 \\
\hline I211 v P31 & 520 & -0.060 & 0.183 & 0.811 & 0.011 \\
\hline I21l v P3w & 531 & 0.151 & 0.182 & 0.435 & 0.00006 \\
\hline I211 v P41 & 553 & -0.160 & 0.738 & 0.272 & $<0.0000001$ \\
\hline I21l v P4w & 554 & 0.228 & -0.063 & 0.171 & $<0.0000001$ \\
\hline I211 v M11 & 550 & 0.287 & -0.211 & 0.049 & $<0.0000001$ \\
\hline I211 v M1mw & 543 & -0.117 & -0.318 & 0.483 & 0.0000001 \\
\hline I21l v M1dw & 544 & -0.314 & -0.063 & 0.059 & 0.0000001 \\
\hline I21l v M21 & 573 & 0.112 & 0.483 & 0.457 & $<0.0000001$ \\
\hline I21l v M2mw & 575 & -0.276 & 0.104 & 0.109 & 0.0000010 \\
\hline I21l v M2dw & 571 & -0.198 & 0.086 & 0.264 & 0.0000007 \\
\hline I21l v M31 & 519 & 0.335 & 0.065 & 0.180 & 0.028 \\
\hline $\mathrm{I} 211 \mathrm{v} \mathrm{M} 3 \mathrm{mw}$ & 564 & -0.085 & 0.204 & 0.632 & 0.0000002 \\
\hline I2ll v M3dw & 537 & -0.249 & 0.161 & 0.320 & 0.048 \\
\hline I2md v P31 & 528 & 0.221 & 0.174 & 0.387 & 0.015 \\
\hline $\mathrm{I} 2 \mathrm{md} v \mathrm{P} 3 \mathrm{w}$ & 538 & 0.163 & 0.162 & 0.414 & 0.00004 \\
\hline I2md v P4l & 560 & -0.006 & 0.564 & 0.968 & $<0.0000001$ \\
\hline $\mathrm{I} 2 \mathrm{md} v \mathrm{P} 4 \mathrm{w}$ & 559 & 0.199 & 0.053 & 0.259 & $<0.0000001$ \\
\hline I2md v M11 & 552 & 0.301 & 0.059 & 0.055 & $<0.0000001$ \\
\hline $\mathrm{I} 2 \mathrm{md} \mathrm{v} \mathrm{M} 1 \mathrm{mw}$ & 545 & -0.094 & 0.024 & 0.595 & 0.0000003 \\
\hline I2md v M1dw & 546 & -0.226 & 0.275 & 0.188 & $<0.0000001$ \\
\hline I2md v M2l & 575 & 0.174 & 0.244 & 0.261 & $<0.0000001$ \\
\hline $\mathrm{I} 2 \mathrm{md} \mathrm{v} \mathrm{M} 2 \mathrm{mw}$ & 576 & -0.007 & -0.124 & 0.968 & $<0.0000001$ \\
\hline $\mathrm{I} 2 \mathrm{md} \mathrm{v} \mathrm{M} 2 \mathrm{dw}$ & 572 & 0.168 & -0.185 & 0.363 & 0.0000006 \\
\hline I2md v M31 & 529 & 0.520 & 0.175 & 0.053 & 0.046 \\
\hline $\mathrm{I} 2 \mathrm{md} \mathrm{v} \mathrm{M} 3 \mathrm{mw}$ & 567 & 0.184 & -0.052 & 0.318 & $<0.0000001$ \\
\hline I2md v M3dw & 547 & 0.477 & -0.147 & 0.085 & 0.127 \\
\hline $\mathrm{P} 31$ v $\mathrm{P} 3 \mathrm{w}$ & 336 & 0.706 & 0.102 & 0.041 & 0.116 \\
\hline P31 v P41 & 403 & 0.917 & 0.038 & 0.00005 & 0.321 \\
\hline $\mathrm{P} 31$ v $\mathrm{P} 4 \mathrm{w}$ & 421 & 0.580 & 0.094 & 0.026 & 0.041 \\
\hline P31 v M11 & 505 & 0.729 & -0.152 & 0.002 & 0.059 \\
\hline P31 v M1mw & 502 & 0.385 & 0.334 & 0.208 & 0.009 \\
\hline P31 v M1dw & 503 & 0.430 & 0.211 & 0.171 & 0.023 \\
\hline P31 v M21 & 547 & 0.640 & 0.192 & 0.005 & 0.019 \\
\hline $\mathrm{P} 31 \mathrm{v} \mathrm{M} 2 \mathrm{mw}$ & 548 & 0.076 & 0.409 & 0.794 & 0.012 \\
\hline $\mathrm{P} 31 \vee \mathrm{M} 2 \mathrm{dw}$ & 542 & 0.158 & 0.472 & 0.641 & 0.035 \\
\hline P31 v M31 & 358 & 0.859 & 0.018 & 0.009 & 0.272 \\
\hline P31 v M3mw & 494 & 0.546 & 0.128 & 0.052 & 0.014 \\
\hline P31 v M3dw & 393 & 0.732 & 0.184 & 0.033 & 0.123 \\
\hline P3w v P4l & 406 & 0.576 & 0.120 & 0.001 & 0.000015 \\
\hline
\end{tabular}


Table 2 Appendix continued

\begin{tabular}{|c|c|c|c|c|c|}
\hline \multirow[t]{2}{*}{ Phenotype pair } & \multirow[t]{2}{*}{$\mathrm{N}$} & \multicolumn{2}{|c|}{$\begin{array}{l}\text { Correlations } \\
\text { (MLEs) }\end{array}$} & \multicolumn{2}{|c|}{$\begin{array}{l}\text { Significance of } \\
\text { correlations } \\
P(\text { Hypothesis })\end{array}$} \\
\hline & & $\rho_{\mathrm{G}}$ & $\rho_{\mathrm{E}}$ & $\rho_{\mathrm{G}}=0$ & $\left|\rho_{\mathrm{G}}\right|=1$ \\
\hline $\mathrm{P} 3 \mathrm{w}$ v $\mathrm{P} 4 \mathrm{w}$ & 423 & 1.000 & -0.098 & $<0.00001$ & $\mathrm{nc}$ \\
\hline P3w v M11 & 517 & 0.313 & 0.584 & 0.091 & 0.00001 \\
\hline $\mathrm{P} 3 \mathrm{w}$ v M1mw & 515 & 0.358 & 0.233 & 0.119 & 0.00004 \\
\hline P3w v M1dw & 516 & 0.051 & 0.757 & 0.821 & 0.00002 \\
\hline P3w v M21 & 551 & 0.612 & 0.052 & 0.0003 & 0.00001 \\
\hline $\mathrm{P} 3 \mathrm{w}$ v $\mathrm{M} 2 \mathrm{mw}$ & 554 & 0.477 & 0.207 & 0.025 & 0.00008 \\
\hline $\mathrm{P} 3 \mathrm{w}$ v M2dw & 547 & 0.514 & 0.163 & 0.028 & 0.0009 \\
\hline P3w v M31 & 391 & 0.437 & 0.142 & 0.202 & 0.0431 \\
\hline $\mathrm{P} 3 \mathrm{w}$ v $\mathrm{M} 3 \mathrm{mw}$ & 510 & 0.469 & -0.012 & 0.045 & 0.0026 \\
\hline P3w v M3dw & 428 & 0.049 & 0.303 & 0.882 & 0.0653 \\
\hline P41 v P4w & 432 & 0.556 & 0.155 & 0.0003 & $<0.0000001$ \\
\hline P41 v M11 & 537 & 0.569 & 0.141 & $<0.0001$ & $<0.0000001$ \\
\hline P41 v M1mw & 535 & 0.536 & -0.316 & 0.001 & $<0.0000001$ \\
\hline P41 v M1dw & 535 & 0.445 & 0.066 & 0.0096 & 0.0000002 \\
\hline P41 v M21 & 556 & 0.729 & 0.262 & $<0.0001$ & $<0.0000001$ \\
\hline $\mathrm{P} 41$ v M2mw & 559 & 0.468 & 0.167 & 0.003 & $<0.0000001$ \\
\hline P41 v M2dw & 555 & 0.474 & 0.218 & 0.004 & $<0.0000001$ \\
\hline P41 v M31 & 439 & 0.646 & 0.253 & 0.001 & 0.010 \\
\hline $\mathrm{P} 41 \mathrm{v} \mathrm{M} 3 \mathrm{mw}$ & 529 & 0.384 & 0.165 & 0.017 & $<0.0000001$ \\
\hline P41 v M3dw & 468 & 0.610 & 0.171 & 0.012 & 0.113 \\
\hline P4w v M11 & 538 & 0.438 & 0.233 & 0.007 & $<0.0000001$ \\
\hline P4w v M1mw & 536 & 0.528 & 0.218 & 0.003 & $<0.0000001$ \\
\hline P4w v M1dw & 537 & 0.345 & 0.348 & 0.069 & $<0.0000001$ \\
\hline $\mathrm{P} 4 \mathrm{w}$ v M21 & 557 & 0.534 & 0.197 & 0.0007 & $<0.0000001$ \\
\hline $\mathrm{P} 4 \mathrm{w}$ v $\mathrm{M} 2 \mathrm{mw}$ & 561 & 0.580 & 0.179 & 0.001 & 0.0000004 \\
\hline $\mathrm{P} 4 \mathrm{w}$ v M2dw & 557 & 0.519 & 0.150 & 0.007 & 0.000005 \\
\hline P4w v M31 & 449 & 0.433 & 0.200 & 0.144 & 0.016 \\
\hline $\mathrm{P} 4 \mathrm{w}$ v M3mw & 534 & 0.577 & 0.032 & 0.001 & 0.00005 \\
\hline P4w v M3dw & 479 & 0.404 & 0.264 & 0.194 & 0.071 \\
\hline M11 v M1mw & 458 & 0.591 & 0.112 & 0.00017 & $<0.0001$ \\
\hline M11 v M1dw & 473 & 0.565 & 0.061 & 0.0008 & 0.0000004 \\
\hline M11 v M21 & 547 & 0.918 & -0.044 & $<0.0001$ & 0.119 \\
\hline M11 v M2mw & 548 & 0.485 & -0.003 & 0.0036 & $<0.0001$ \\
\hline M11 v M2dw & 547 & 0.371 & 0.211 & 0.033 & 0.0000007 \\
\hline M11 v M31 & 495 & 0.744 & 0.400 & 0.0023 & 0.054 \\
\hline M11 v M3mw & 555 & 0.578 & 0.073 & 0.0007 & 0.00005 \\
\hline M11 v M3dw & 523 & 0.280 & 0.242 & 0.207 & 0.009 \\
\hline M1mw v M1dw & 445 & 0.933 & 0.492 & $<0.0001$ & 0.0008 \\
\hline M1mw v M21 & 543 & 0.555 & -0.127 & 0.0004 & $<0.0001$ \\
\hline $\mathrm{M} 1 \mathrm{mw}$ v M2mw & 543 & 0.865 & 0.362 & $<0.0001$ & 0.0019 \\
\hline M1mw v M2dw & 541 & 0.761 & 0.312 & 0.00004 & 0.0005 \\
\hline M1mw v M31 & 482 & 0.544 & -0.063 & 0.065 & 0.037 \\
\hline M1mw v M3mw & 535 & 0.770 & 0.042 & $<0.0001$ & 0.00055 \\
\hline M1mw v M3dw & 502 & 0.208 & 0.448 & 0.49 & 0.037 \\
\hline M1dw v M2l & 544 & 0.466 & -0.297 & 0.0027 & $<0.0001$ \\
\hline
\end{tabular}

Table 2 Appendix continued

\begin{tabular}{|c|c|c|c|c|c|}
\hline \multirow[t]{2}{*}{ Phenotype pair } & \multirow[t]{2}{*}{$\mathrm{N}$} & \multicolumn{2}{|c|}{$\begin{array}{l}\text { Correlations } \\
\text { (MLEs) }\end{array}$} & \multicolumn{2}{|c|}{$\begin{array}{l}\text { Significance of } \\
\text { correlations } \\
P(\text { Hypothesis })\end{array}$} \\
\hline & & $\rho_{\mathrm{G}}$ & $\rho_{\mathrm{E}}$ & $\rho_{\mathrm{G}}=0$ & $\left|\rho_{\mathrm{G}}\right|=1$ \\
\hline M1dw v M2mw & 543 & 0.790 & 0.152 & $<0.0001$ & 0.00018 \\
\hline M1dw v M2dw & 542 & 0.737 & 0.298 & 0.00005 & 0.000007 \\
\hline M1dw v M31 & 485 & 0.167 & 0.267 & 0.638 & 0.022 \\
\hline M1dw v M3mw & 534 & 0.583 & 0.064 & 0.002 & 0.00008 \\
\hline M1dw v M3dw & 523 & 0.286 & 0.232 & 0.192 & 0.009 \\
\hline $\mathrm{M} 21 \mathrm{v} \mathrm{M} 2 \mathrm{mw}$ & 536 & 0.693 & 0.202 & $<0.0001$ & 0.000006 \\
\hline $\mathrm{M} 21$ v M2dw & 535 & 0.619 & 0.296 & 0.00011 & $<0.0001$ \\
\hline M21 v M31 & 514 & 0.947 & 0.346 & $<0.0001$ & 0.303 \\
\hline M21 v M3mw & 551 & 0.673 & 0.084 & 0.00005 & 0.0003 \\
\hline M21 v M3dw & 548 & 0.267 & 0.476 & 0.212 & 0.012 \\
\hline $\mathrm{M} 2 \mathrm{mw}$ v M2dw & 531 & 0.821 & 0.734 & 0.00001 & 0.0000005 \\
\hline M2mw v M31 & 542 & 0.625 & 0.180 & 0.031 & 0.060 \\
\hline $\mathrm{M} 2 \mathrm{mw}$ v M3mw & 552 & 0.880 & 0.335 & $<0.0001$ & 0.068 \\
\hline M2mw v M3dw & 549 & 0.397 & 0.576 & 0.303 & 0.154 \\
\hline M2dw v M31 & 321 & 0.520 & 0.681 & 0.113 & 0.007 \\
\hline M2dw v M3mw & 543 & 0.523 & 0.487 & 0.011 & 0.0000005 \\
\hline M2dw v M3dw & 539 & 0.709 & 0.596 & 0.031 & 0.117 \\
\hline M31 v M3mw & 453 & 0.608 & 0.669 & 0.018 & 0.012 \\
\hline M31 v M3dw & 321 & 0.520 & 0.681 & 0.113 & 0.007 \\
\hline M3mw v M3dw & 446 & 0.564 & 0.716 & 0.048 & 0.015 \\
\hline \multicolumn{6}{|c|}{ Baboon left maxillary } \\
\hline I11l v I1md & 471 & 0.447 & 0.233 & 0.007 & $<0.0001$ \\
\hline I111 v I211 & 484 & 0.921 & 0.332 & $<0.0001$ & 0.067 \\
\hline I11l v I2md & 471 & 0.654 & -0.08 & $<0.001$ & 0.0017 \\
\hline I11l v P31 & 531 & 0.626 & -0.131 & 0.065 & 0.19 \\
\hline I11l v P3w & 537 & 0.524 & -0.090 & 0.076 & 0.049 \\
\hline I111 v P41 & 565 & 0.177 & 0.174 & 0.347 & $<0.0001$ \\
\hline I11l v P4w & 568 & 0.519 & -0.228 & 0.008 & 0.0004 \\
\hline I111 v M11 & 557 & 0.080 & 0.339 & 0.67 & $<0.0001$ \\
\hline I111 v M1mw & 550 & -0.318 & 0.142 & 0.104 & $<0.0001$ \\
\hline I11l v M1dw & 549 & -0.280 & 0.185 & 0.145 & $<0.0001$ \\
\hline I11l v M21 & 580 & 0.340 & 0.098 & 0.031 & 0.0000003 \\
\hline I11l v M2mw & 579 & -0.303 & 0.178 & 0.126 & 0.000012 \\
\hline I11l v M2dw & 469 & 1.000 & 0.987 & $<0.0001$ & $\mathrm{nc}$ \\
\hline I111 v M31 & 538 & 0.511 & 0.097 & 0.131 & 0.132 \\
\hline I11l v M3mw & 566 & -0.174 & 0.108 & 0.532 & 0.0062 \\
\hline I11l v M3dw & 549 & -0.280 & 0.185 & 0.145 & $<0.0001$ \\
\hline I1md v I21l & 485 & 0.367 & -0.053 & 0.018 & $<0.0000001$ \\
\hline $\mathrm{I} 1 \mathrm{md}$ v I2md & 485 & 0.482 & 0.109 & 0.004 & 0.0000073 \\
\hline I1md v P31 & 533 & 0.0346 & 0.297 & 0.907 & 0.0576 \\
\hline I1md v P3w & 539 & -0.070 & 0.250 & 0.780 & 0.0071 \\
\hline I1md v P4l & 566 & 0.129 & 0.389 & 0.423 & $<0.0000001$ \\
\hline I1md v P4w & 568 & 0.372 & -0.146 & 0.014 & $<0.0000001$ \\
\hline I1md v M11 & 557 & 0.133 & 0.484 & 0.353 & $<0.0000001$ \\
\hline I1md v M1mw & 550 & 0.149 & 0.087 & 0.335 & $<0.0000001$ \\
\hline
\end{tabular}


Table 2 Appendix continued

\begin{tabular}{|c|c|c|c|c|c|}
\hline \multirow[t]{2}{*}{ Phenotype pair } & \multirow[t]{2}{*}{$\mathrm{N}$} & \multicolumn{2}{|c|}{$\begin{array}{l}\text { Correlations } \\
\text { (MLEs) }\end{array}$} & \multicolumn{2}{|c|}{$\begin{array}{l}\text { Significance of } \\
\text { correlations } \\
P(\text { Hypothesis })\end{array}$} \\
\hline & & $\rho_{\mathrm{G}}$ & $\rho_{\mathrm{E}}$ & $\rho_{\mathrm{G}}=0$ & $\left|\rho_{\mathrm{G}}\right|=1$ \\
\hline I1md v M1dw & 549 & 0.085 & 0.235 & 0.561 & $<0.0000001$ \\
\hline I1md v M21 & 580 & 0.226 & 0.466 & 0.076 & $<0.0000001$ \\
\hline $\mathrm{I} 1 \mathrm{md} \mathrm{v} \mathrm{M} 2 \mathrm{mw}$ & 579 & 0.108 & 0.260 & 0.470 & $<0.0000001$ \\
\hline I1md v M2dw & 575 & 0.348 & -0.067 & 0.022 & 0.0000001 \\
\hline I1md v M31 & 540 & 0.991 & -0.333 & 0.001 & 0.491 \\
\hline I1md v M3mw & 567 & 0.194 & 0.043 & 0.379 & 0.002 \\
\hline I1md v M3dw & 548 & 0.446 & -0.079 & 0.067 & 0.047 \\
\hline I 211 v I2md & 471 & 0.660 & -0.079 & 0.0004 & 0.002 \\
\hline I211 v P31 & 524 & 0.414 & 0.024 & 0.187 & 0.095 \\
\hline I21l v P3w & 534 & 0.071 & 0.147 & 0.792 & 0.007 \\
\hline I211 v P41 & 582 & 0.001 & 0.590 & 0.995 & $<0.0000001$ \\
\hline I2ll v P4w & 565 & 0.175 & -0.005 & 0.332 & $<0.0000001$ \\
\hline I211 v M11 & 558 & 0.107 & -0.007 & 0.540 & $<0.0000001$ \\
\hline I211 v M1mw & 551 & -0.343 & 0.303 & 0.059 & $<0.0000001$ \\
\hline I2ll v M1dw & 550 & -0.296 & 0.349 & 0.089 & $<0.0000001$ \\
\hline I211 v M21 & 579 & 0.181 & 0.208 & 0.226 & $<0.0000001$ \\
\hline I21l v M2mw & 578 & -0.303 & 0.256 & 0.096 & 0.0000004 \\
\hline I211 v M2dw & 574 & 0.022 & -0.031 & 1.00 & $<0.0000001$ \\
\hline I21l v M31 & 532 & 0.113 & 0.158 & 0.688 & 0.054 \\
\hline $\mathrm{I} 211 \mathrm{v} \mathrm{M} 3 \mathrm{mw}$ & 566 & -0.443 & 0.242 & 0.074 & 0.026 \\
\hline I21l v M3dw & 542 & -0.438 & 0.548 & 0.087 & 0.029 \\
\hline I2md v P31 & 529 & 0.250 & 0.217 & 0.459 & 0.069 \\
\hline $\mathrm{I} 2 \mathrm{md}$ v P3w & 536 & 0.223 & 0.064 & 0.430 & 0.0061 \\
\hline I2md v P4l & 583 & 0.362 & 0.410 & 0.054 & 0.0000004 \\
\hline $\mathrm{I} 2 \mathrm{md}$ v $\mathrm{P} 4 \mathrm{w}$ & 565 & 0.243 & -0.034 & 0.218 & 0.0000001 \\
\hline I2md v M11 & 559 & 0.230 & 0.064 & 0.228 & 0.0000014 \\
\hline $\mathrm{I} 2 \mathrm{md} \mathrm{v} \mathrm{M} 1 \mathrm{mw}$ & 553 & -0.088 & 0.108 & 0.663 & 0.0000003 \\
\hline $\mathrm{I} 2 \mathrm{md} \mathrm{v} \mathrm{M} 1 \mathrm{dw}$ & 552 & -0.076 & 0.070 & 0.694 & 0.0000001 \\
\hline $\mathrm{I} 2 \mathrm{md}$ v M2l & 580 & 0.093 & 0.517 & 0.566 & 0.0000001 \\
\hline $\mathrm{I} 2 \mathrm{md} \mathrm{v} \mathrm{M} 2 \mathrm{mw}$ & 579 & -0.130 & 0.296 & 0.498 & 0.0000003 \\
\hline $\mathrm{I} 2 \mathrm{md} \mathrm{v} \mathrm{M} 2 \mathrm{dw}$ & 575 & 0.103 & 0.134 & 0.600 & 0.0000001 \\
\hline I2md v M31 & 538 & 0.595 & 0.022 & 0.129 & 0.224 \\
\hline $\mathrm{I} 2 \mathrm{md} \mathrm{v} \mathrm{M} 3 \mathrm{mw}$ & 567 & 0.131 & 0.045 & 0.624 & 0.002 \\
\hline $\mathrm{I} 2 \mathrm{md} v \mathrm{M} 3 \mathrm{dw}$ & 547 & 0.350 & 0.137 & 0.207 & 0.016 \\
\hline $\mathrm{P} 31$ v $\mathrm{P} 3 \mathrm{w}$ & 348 & 0.517 & 0.329 & 0.201 & 0.055 \\
\hline P31 v P41 & 428 & 0.554 & 0.207 & 0.036 & 0.023 \\
\hline $\mathrm{P} 31$ v $\mathrm{P} 4 \mathrm{w}$ & 465 & 0.568 & 0.454 & 0.013 & 0.006 \\
\hline P31 v M11 & 519 & 0.514 & 0.177 & 0.066 & 0.056 \\
\hline P31 v M1mw & 516 & 0.511 & 0.190 & 0.065 & 0.026 \\
\hline P31 v M1dw & 516 & 0.472 & 0.124 & 0.136 & 0.077 \\
\hline P31 v M21 & 553 & 0.517 & 0.274 & 0.035 & 0.037 \\
\hline $\mathrm{P} 31$ v $\mathrm{M} 2 \mathrm{mw}$ & 555 & -0.117 & 0.548 & 0.67 & 0.022 \\
\hline $\mathrm{P} 31$ v M2dw & 550 & -0.068 & 0.484 & 1.00 & 0.027 \\
\hline P31 v M31 & 374 & -0.182 & 0.577 & 0.700 & 0.093 \\
\hline P31 v M3mw & 499 & -0.002 & 0.315 & 0.031 & 0.996 \\
\hline
\end{tabular}

Table 2 Appendix continued

\begin{tabular}{|c|c|c|c|c|c|}
\hline \multirow[t]{2}{*}{ Phenotype pair } & \multirow[t]{2}{*}{$\mathrm{N}$} & \multicolumn{2}{|c|}{$\begin{array}{l}\text { Correlations } \\
\text { (MLEs) }\end{array}$} & \multicolumn{2}{|c|}{$\begin{array}{l}\text { Significance of } \\
\text { correlations } \\
P(\text { Hypothesis })\end{array}$} \\
\hline & & $\rho_{\mathrm{G}}$ & $\rho_{\mathrm{E}}$ & $\rho_{\mathrm{G}}=0$ & $\left|\rho_{\mathrm{G}}\right|=1$ \\
\hline P31 v M3dw & 401 & -0.440 & 0.421 & 0.487 & 0.254 \\
\hline P3w v P4l & 427 & 0.416 & 0.406 & 0.108 & 0.009 \\
\hline $\mathrm{P} 3 w$ v $\mathrm{P} 4 \mathrm{w}$ & 442 & 0.865 & 0.487 & $<0.0001$ & 0.063 \\
\hline P3w v M11 & 525 & 0.505 & 0.309 & 0.024 & 0.002 \\
\hline $\mathrm{P} 3 \mathrm{w}$ v M1mw & 519 & 0.550 & 0.420 & 0.025 & 0.013 \\
\hline P3w v M1dw & 519 & 0.366 & 0.559 & 0.140 & 0.007 \\
\hline $\mathrm{P} 3 \mathrm{w}$ v M21 & 554 & 0.451 & 0.349 & 0.030 & 0.0009 \\
\hline $\mathrm{P} 3 \mathrm{w}$ v $\mathrm{M} 2 \mathrm{mw}$ & 558 & 0.572 & 0.261 & 0.008 & 0.0008 \\
\hline $\mathrm{P} 3 \mathrm{w}$ v M2dw & 552 & 0.350 & 0.284 & 0.139 & 0.0009 \\
\hline P3w v M31 & 411 & -0.527 & 0.432 & 0.284 & 0.237 \\
\hline $\mathrm{P} 3 \mathrm{w}$ v $\mathrm{M} 3 \mathrm{mw}$ & 511 & 0.411 & 0.221 & 0.224 & 0.004 \\
\hline P3w v M3dw & 441 & -0.686 & 0.436 & 0.171 & 0.281 \\
\hline $\mathrm{P} 41 \vee \mathrm{P} 4 \mathrm{w}$ & 451 & 0.620 & 0.241 & 0.0001 & $<0.0001$ \\
\hline P41 v M11 & 549 & 0.663 & 0.167 & $<0.0001$ & $<0.0001$ \\
\hline P41 v M1mw & 548 & 0.498 & 0.149 & 0.003 & $<0.0001$ \\
\hline P41 v M1dw & 549 & 0.520 & 0.177 & 0.001 & $<0.0001$ \\
\hline P41 v M21 & 561 & 0.663 & 0.431 & $<0.0001$ & $<0.0001$ \\
\hline $\mathrm{P} 41$ v M2mw & 565 & 0.445 & 0.108 & 0.008 & $<0.0001$ \\
\hline $\mathrm{P} 41 \mathrm{v} \mathrm{M} 2 \mathrm{dw}$ & 560 & 0.523 & -0.042 & 0.001 & $<0.0001$ \\
\hline P41 v M31 & 463 & 0.402 & 0.432 & 0.122 & 0.023 \\
\hline P41 v M3mw & 537 & 0.466 & 0.115 & 0.035 & 0.0006 \\
\hline $\mathrm{P} 41 \vee \mathrm{M} 3 \mathrm{dw}$ & 494 & 0.271 & 0.384 & 0.318 & 0.008 \\
\hline P4w v M11 & 550 & 0.600 & -0.128 & $<0.0001$ & $<0.0001$ \\
\hline $\mathrm{P} 4 \mathrm{w}$ v M1mw & 548 & 0.773 & -0.125 & 0.0001 & 0.0001 \\
\hline P4w v M1dw & 549 & 0.665 & 0.017 & $<0.0001$ & $<0.0001$ \\
\hline $\mathrm{P} 4 \mathrm{w}$ v M21 & 561 & 0.628 & -0.093 & $<0.0001$ & $<0.0001$ \\
\hline $\mathrm{P} 4 \mathrm{w}$ v $\mathrm{M} 2 \mathrm{mw}$ & 565 & 0.682 & 0.060 & $<0.0001$ & $<0.0001$ \\
\hline $\mathrm{P} 4 \mathrm{w}$ v M2dw & 561 & 0.515 & 0.222 & 0.0019 & $<0.0001$ \\
\hline P4w v M31 & 478 & 0.251 & 0.250 & 0.453 & 0.069 \\
\hline $\mathrm{P} 4 \mathrm{w}$ v M3mw & 541 & 0.691 & 0.255 & 0.0008 & 0.0015 \\
\hline P4w v M3dw & 506 & 0.133 & 0.458 & 0.698 & 0.014 \\
\hline M11 v M1mw & 474 & 0.669 & -0.123 & $<0.0001$ & $<0.0001$ \\
\hline M11 v M1dw & 474 & 0.714 & -0.399 & $<0.0001$ & $<0.0001$ \\
\hline M11 v M21 & 554 & 0.928 & -0.153 & $<0.0001$ & 0.093 \\
\hline M11 v M2mw & 555 & 0.602 & -0.086 & $<0.0001$ & $<0.0001$ \\
\hline M11 v M2dw & 553 & 0.498 & 0.104 & 0.002 & $<0.0001$ \\
\hline M11 v M31 & 516 & 0.896 & 0.202 & $<0.0001$ & 0.123 \\
\hline M11 v M3mw & 542 & 0.839 & 0.023 & $<0.0001$ & 0.040 \\
\hline M11 v M3dw & 537 & 0.326 & 0.208 & 0.145 & 0.002 \\
\hline M1mw v M1dw & 465 & 0.866 & 0.705 & $<0.0001$ & $<0.0001$ \\
\hline M1mw v M21 & 553 & 0.627 & -0.336 & $<0.0001$ & $<0.0001$ \\
\hline M1mw v M2mw & 553 & 0.890 & 0.071 & $<0.0001$ & $<0.0001$ \\
\hline M1mw v M2dw & 551 & 0.801 & 0.164 & $<0.0001$ & 0.0013 \\
\hline M1mw v M31 & 510 & 0.675 & 0.099 & 0.014 & 0.125 \\
\hline M1mw v M3mw & 539 & 0.885 & 0.181 & $<0.0001$ & 0.080 \\
\hline
\end{tabular}


Table 2 Appendix continued

\begin{tabular}{|c|c|c|c|c|c|}
\hline \multirow[t]{2}{*}{ Phenotype pair } & \multirow[t]{2}{*}{$\mathrm{N}$} & \multicolumn{2}{|c|}{$\begin{array}{l}\text { Correlations } \\
\text { (MLEs) }\end{array}$} & \multicolumn{2}{|c|}{$\begin{array}{l}\text { Significance of } \\
\text { correlations } \\
P \text { (Hypothesis })\end{array}$} \\
\hline & & $\rho_{\mathrm{G}}$ & $\rho_{\mathrm{E}}$ & $\rho_{\mathrm{G}}=0$ & $\left|\rho_{\mathrm{G}}\right|=1$ \\
\hline M1mw v M3dw & 513 & 0.624 & 0.008 & 0.009 & 0.044 \\
\hline M1dw v M2l & 553 & 0.615 & -0.539 & $<0.0001$ & $<0.0001$ \\
\hline M1dw v M2mw & 553 & 0.780 & 0.120 & $<0.0001$ & $<0.0001$ \\
\hline M1dw v M2dw & 550 & 0.800 & 0.303 & $<0.0001$ & $<0.0001$ \\
\hline M1dw v M31 & 509 & 0.485 & 0.339 & 0.117 & 0.064 \\
\hline M1dw v M3mw & 540 & 0.718 & 0.259 & 0.0006 & 0.005 \\
\hline M1dw v M3dw & 513 & 0.605 & 0.186 & 0.010 & 0.020 \\
\hline M21 v M2mw & 548 & 0.677 & -0.029 & $<0.0001$ & $<0.0001$ \\
\hline M21 v M2dw & 547 & 0.604 & 0.203 & $<0.0001$ & $<0.0001$ \\
\hline M21 v M31 & 548 & 0.828 & 0.286 & 0.0003 & 0.196 \\
\hline M21 v M3mw & 552 & 0.878 & -0.012 & $<0.0001$ & 0.095 \\
\hline M21 v M3dw & 551 & 0.549 & 0.000 & 0.0029 & 0.0011 \\
\hline $\mathrm{M} 2 \mathrm{mw}$ v M2dw & 541 & 0.903 & 0.474 & $<0.0001$ & 0.0023 \\
\hline M2mw v M31 & 549 & 0.904 & -0.041 & 0.0008 & 0.342 \\
\hline $\mathrm{M} 2 \mathrm{mw}$ v M3mw & 557 & 1.00 & 0.347 & $<0.0001$ & $\mathrm{nc}$ \\
\hline M2mw v M3dw & 553 & 0.746 & 0.092 & 0.0001 & 0.0159 \\
\hline M2dw v M31 & 542 & 0.903 & 0.064 & 0.002 & 0.349 \\
\hline M2dw v M3mw & 549 & 0.867 & 0.272 & $<0.0001$ & 0.060 \\
\hline $\mathrm{M} 2 \mathrm{dw} v \mathrm{M} 3 \mathrm{dw}$ & 545 & 0.914 & 0.149 & $<0.0001$ & 0.19 \\
\hline M31 v M3mw & 456 & 0.697 & 0.505 & 0.112 & 0.189 \\
\hline M31 v M3dw & 347 & 0.697 & 0.508 & 0.078 & 0.106 \\
\hline M3mw v M3dw & 443 & 0.457 & 0.693 & 0.26 & 0.0058 \\
\hline
\end{tabular}

${ }^{a}$ MLE maximum likelihood estimate; $P$ (Hypothesis) probability of the hypothesis (indicated in columns below) being true given the available pedigreed data; $n c$ not computable; all phenotypes indicated with $*$ in Table 1 were i-normalized in the bivariate analyses

\section{References}

Ackermann, R. R. (2007). Craniofacial variation and developmental divergence in primate and human evolution. Novartis Foundation Symposium, 284, 262-273. doi:10.1002/9780470319390.ch17.

Ackermann, R. R., \& Cheverud, J. M. (2000). Phenotypic covariance structure in tamarins (genus Saguinus): A comparison of variation patterns using matrix correlation and common principal component analysis. American Journal of Physical Anthropology, 111, 489-501. doi:10.1002/(SICI)1096-8644(200004)111: 4<489::AID-AJPA5>3.0.CO;2-U.

Ackermann, R. R., \& Cheverud, J. M. (2002). Discerning evolutionary processes in patterns of tamarin (genus Saguinus) craniofacial variation. American Journal of Physical Anthropology, 117, 260-271. doi:10.1002/ajpa.10038.

Almasy, L., \& Blangero, J. (1998). Multipoint quantitative-trait linkage analysis in general pedigrees. American Journal of Human Genetics, 62, 1198-1211. doi:10.1086/301844.

Arnold, S. J. (1992). Constraints on phenotypic evolution. American Naturalist, 140, 85-107. doi:10.1086/285398.

Arnold, S. J., \& Phillips, P. C. (1999). Hierarchical comparisons of genetic variance-covariance matrices. II. Coastal-inland divergence in the garter snake, Thamnophis elegans. Evolution, 53, 1516-1527. doi:10.2307/2640897.
Bateson, W. (1892). On numerical variation in teeth, with a discussion of the conception of homology. Proceedings of the Zoological Society of London, 1892, 102-105.

Bateson, W. (1894). Material for the study of variation, treated with special regard to discontinuity in the origin of species. London: Macmillan.

Boehnke, M., Moll, P. P., Kottke, B. A., \& Weidman, W. H. (1987). Paritioning the variability of fasting plasma glucose levels in pedigrees. American Journal of Epidemiology, 125, 679-689.

Butler, P. M. (1939). Studiesn of the mammalian dentition, differentiation of the post-canine dentition. Proceedings of the Zoological Society of London, 109, B1-B36.

Butler, P. M. (1956). The ontogeny of molar pattern. Biological Reviews of the Cambridge Philosophical Society, 31, 30. doi: 10.1111/j.1469-185X.1956.tb01551.x.

Caruso, C. M., Maherali, H., Mikulyuk, A., Carson, K., \& Jackson, R. B. (2005). Genetic variance and covariance for physiological traits in Lobelia: Are there constraints on adaptive evolution? Evolution, 59, 826-837.

Cheverud, J. M. (1982). Phenotypic, genetic, and environmental morphological integration in the cranium. Evolution, 36, 499516. doi:10.2307/2408096.

Cheverud, J. M. (1988). A comparison of genetic and phenotypic correlations. Evolution, 42(5), 958-968. doi:10.2307/2408911.

Cheverud, J. M. (1989). A comparative analysis of morphological variation patterns in the papionins. Evolution, 43, 1737-1747. doi: $10.2307 / 2409389$.

Cheverud, J. M. (1995). Morphological integration in the saddle-back tamarin (Saguinus fuscicollis) cranium. American Naturalist, 145, 63-89. doi:10.1086/285728.

Cheverud, J. M. (1996a). Developmental integration and the evolution of pleiotropy. American Zoologist, 36(1), 44-50.

Cheverud, J. M. (1996b). Quantitative genetic analysis of cranial morphology in the cotton-top (Saguinus oedipus) and saddleback (S. fuscicollis) tamarins. Journal of Evolutionary Biology, 9, 5-42. doi:10.1046/j.1420-9101.1996.9010005.x.

Cheverud, J. M., Rutledge, J. J., \& Atchley, W. R. (1983). Quantitative genetics of development: Genetic correlations among age-specific trait values and the evolution of ontogeny. Evolution, 37, 895-905. doi:10.2307/2408405.

Cheverud, J. M., Wagner, G. P., \& Dow, M. M. (1989). Methods for the comparative analysis of variation patterns. Systematic Zoology, 38(3), 201-213. doi:10.2307/2992282.

Cobourne, M. T., \& Sharpe, P. T. (2003). Tooth and jaw: Molecular mechanisms of patterning in the first branchial arch. Archives of Oral Biology, 48, 1-14. doi:10.1016/S0003-9969(02)00208-X.

Colosimo, P. F., Hosemann, K. E., Balabhadra, S., Villarreal, G., Jr., Dickson, M., Grimwood, J., et al. (2005). Widespread parallel evolution in sticklebacks by repeated fixation of Ectodysplasin alleles. Science, 307(5717), 1928-1933. doi:10.1126/science. 1107239.

Dahlberg, A. A. (1945). The changing dentition of man. The Journal of the American Dental Association, 32, 676-690.

Dyke, B. (1996). PEDSYS: A pedigree data management software. San Antonio, Texas: Southwest Foundation for Biomedical Research.

Gingerich, P. D. (1974). Stratigraphic record of early Eocene Hyopsodus and the geometry of mammalian phylogeny. Nature, 248, 107-109. doi:10.1038/248107a0.

Henderson, A. M., \& Greene, D. L. (1975). Dental field theory: An application to primate evolution. Journal of Dental Research, 54, $344-350$

Hlusko, L. J. (2004). Perspective: Integrating the genotype and phenotype in hominid paleontology. Proceedings of the National Academy of Sciences of the United States of America, 101(9), 2653-2657. doi:10.1073/pnas.0307678101. 
Hlusko, L. J., Lease, L. R., \& Mahaney, M. C. (2006). The evolution of genetically correlated traits: Tooth size and body size in baboons. American Journal of Physical Anthropology, 131, 420-427. doi:10.1002/ajpa.20435.

Hlusko, L. J., Maas, M. L., \& Mahaney, M. C. (2004a). Statistical genetics of molar cusp patterning in pedigreed baboons: Implications for primate dental development and evolution. Journal of Experimental Zoology. Part B. Molecular and Developmental Evolution, 302B, 268-283. doi:10.1002/ jez.b.21.

Hlusko, L. J., \& Mahaney, M. C. (2003). Genetic contributions to expression of the baboon cingular remnant. Archives of Oral Biology, 48, 663-672. doi:10.1016/S0003-9969(03)00132-8.

Hlusko, L. J., \& Mahaney, M. C. (2007a). A multivariate comparison of dental variation in wild and captive populations of baboons (Papio hamadryas). Archives of Oral Biology, 52, 195-200. doi: 10.1016/j.archoralbio.2006.09.008.

Hlusko, L. J., \& Mahaney, M. C. (2007b). Of mice and monkeys: Quantitative genetic analyses of size variation along the dental arcade. In S. Bailey \& J.-J. Hublin (Eds.), Dental perspectives on human evolution: State of the art research in dental paleoanthropology (pp. 237-245). Dordrecht: Springer.

Hlusko, L. J., \& Mahaney, M. C. (2008). Baboon model for dental development. In J. L. VandeBerg, S. Williams-Blanger, \& S. D. Tardif (Eds.), The baboon in biomedical research. Developments in primatology: Progress and prospects. New York: Kluwer Academic.

Hlusko, L. J., Mahaney, M. C., \& Weiss, K. M. (2002). A statistical genetic comparison of two techniques for assessing molar crown size in pedigreed baboons. American Journal of Physical Anthropology, 117(2), 182-189. doi:10.1002/ajpa.10022.

Hlusko, L. J., Suwa, G., Kono, R., \& Mahaney, M. C. (2004b). Genetics and the evolution of primate enamel thickness: A baboon model. American Journal of Physical Anthropology, 124, 223-233. doi:10.1002/ajpa.10353.

Hopper, J. L., \& Mathews, J. D. (1982). Extensions to multivariate normal models for pedigree analysis. Annals of Human Genetics, 46, 373-383. doi:10.1111/j.1469-1809.1982.tb01588.x.

James, C. T., Ohazama, A., Tucker, A. S., \& Sharpe, P. T. (2002). Tooth development is independent of a Hox patterning programme. Developmental Dynamics, 225, 332-335. doi: $10.1002 /$ dvdy. 10168 .

Jernvall, J. (2000). Linking development with generation of novelty in mammalian teeth. Proceedings of the National Academy of Sciences of the United States of America, 97, 2641-2645. doi: 10.1073/pnas.050586297.

Jernvall, J., \& Thesleff, I. (2000). Reiterative signaling and patterning during mammalian tooth morphogenesis. Mechanisms of Development, 92, 19-29. doi:10.1016/S0925-4773(99)00322-6.

Jolly, C. J. (1993). Species, subspecies, and baboon systematics. In W. H. Kimbel \& L. B. Martin (Eds.), Species, species concepts, and primate evolution (pp. 67-107). New York: Plenum Press.

Kapadia, H., Mues, G., \& D'Souza, R. (2007). Genes affecting tooth morphogenesis. Orthodontics and Craniofacial Research, 10, 237-244. doi:10.1111/j.1601-6343.2007.00407.x.

Kassai, Y., Munne, P., Hotta, Y., Penttila, E., Kavanagh, K., Ohbayashi, N., et al. (2005). Regulation of mammalian tooth cusp patterning by ectodin. Science, 309, 2067-2070. doi: 10.1126/science. 1116848 .

Keränen, S. V. E., Åberg, T., Kettunen, P., Thesleff, I., \& Jernvall, J. (1998). Association of developmental regulatory genes with the development of different molar tooth shapes in two species of rodents. Development Genes and Evolution, 208, 477-486. doi: $10.1007 / \mathrm{s} 004270050206$.

Koentges, G. (2008). Evolution of anatomy and gene control. Nature, 451, 658-663. doi:10.1038/451658a.
Kohn, L. A., Leigh, S. R., Jacobs, S. C., \& Cheverud, J. M. (1993). Effects of annular cranial vault modification on the cranial base and face. American Journal of Physical Anthropology, 90, 147-168. doi:10.1002/ajpa.1330900203.

Koots, K. R., \& Gibson, J. P. (1996). Realized sampling variances of estimates of genetic parameters and the difference between genetic and phenotypic correlations. Genetics, 143, 1409-1416.

Lande, R. (1979). Quantitative genetic analysis of multivariate evolution, applied to brain:body size allometry. Evolution, 33, 402-416. doi:10.2307/2407630.

Lande, R. (1980). Genetic variation and phenotypic evolution during allopatric speciation. American Naturalist, 116(4), 463-479. doi: $10.1086 / 283642$.

Lange, K., \& Boehnke, M. (1983). Extensions to pedigree analysis. IV. Covariance components models for multivariate traits. American Journal of Medical Genetics, 14, 513-524. doi: 10.1002/ajmg.1320140315.

Lin, D., Huang, Y., He, F., Gu, S., Zhang, G., Chen, Y., et al. (2007). Expression survey of genes critical for tooth development in the human embryonic tooth germ. Developmental Dynamics, 236, 1307-1312. doi:10.1002/dvdy.21127.

Lombardi, A. V. (1975). A factor analysis of morphogenetic fields in the human dentition. American Journal of Physical Anthropology, 42, 99-104. doi:10.1002/ajpa.1330420114.

Lynch, M., \& Walsh, B. (1998). Genetics and analysis of quantitative traits. Sunderland, MA: Sinauer Associates, Inc.

Magwene, P. M. (2001). New tools for studying integration and modularity. Evolution, 55(9), 1734-1745.

Mahaney, M. C., Blangero, J., Comuzzie, A. G., VandeBerg, J. L., Stern, M. P., \& MacCluer, J. W. (1995). Plasma HDL cholesterol, triglycerides, and adiposity. A quantitative genetic test of the conjoint trait hypothesis in the San Antonio Family Heart Study. Circulation, 92, 3240-3248.

Mantel, N. (1967). The detection of disease clustering and a generalized regression approach. Cancer Research, 27, 209-220.

Marroig, G., \& Cheverud, J. M. (2005). Size as a line of least evolutionary resistance: Diet and adaptive morphological radiation in New World monkeys. Evolution, 59, 1128-1142.

Marroig, G., DeVivo, M., \& Cheverud, J. M. (2004). Cranial evolution in sakis (Pithecia, Platyrrhini). II. Evolutionary processes and morphological integration. Journal of Evolutionary Biology, 17, 144-155. doi:10.1046/j.1420-9101.2003.00653.x.

Mezey, J., Cheverud, J. M., \& Wagner, G. (2000). Is the genotypephenotype map modular? A statistical approach using mouse QTL data. Genetics, 156, 305-311.

Mitteroecker, P., \& Bookstein, F. (2008). The evolutionary role of modularity and integration in the hominoid cranium. Evolution, 62, 943-958. doi:10.1111/j.1558-5646.2008.00321.x.

Miyado, M., Ogi, H., Yamada, G., Kitoh, J., Jogahara, T., Oda, S., et al. (2007). Sonic hedgehog expression during early tooth development in Suncus murinus. Biochemical and Biophysical Research Communications, 363, 269-275. doi:10.1016/j.bbrc. 2007.08.158.

National Research Council. (1996). Guide for the care and use of laboratory animals. Washington, DC: National Academy Press.

Nemeschkal, H. L. (1999). Morphometric correlation patterns of adult birds (Fringillidae: Passeriformes and Columbiformes) mirror the expression of developmental control genes. Evolution, 53(2), 899-918. doi:10.2307/2640730.

Olson, E. C., \& Miller, R. L. (1958). Morphological integration. Chicago: University of Chicago Press.

Osborn, J. W. (1978). Morphogenetic gradients: Fields vs clones. In P. M. Butler \& K. A. Joysey (Eds.), Development, function and evolution of teeth (pp. 171-201). New York: Academic Press. 
Phillips, P. C., \& Arnold, S. J. (1999). Hierarchical comparison of genetic variance-covarience matrices. I. using the flury hierarchy. Evolution, 53(5), 1506-1515. doi:10.2307/2640896.

Reno, P. L., McCollum, M. A., Cohn, M. J., Meindl, R. S., Hamrick, M., \& Lovejoy, C. O. (2008). Patterns of correlation and covariation of anthropoid distal forelimb segments correspond to Hoxd expression territories. Journal of Experimental Zoology. Part B. Molecular and Developmental Evolution, 310B, 240-258. doi:10.1002/jez.b.21207.

Richtsmeier, J. T., Cheverud, J. M., \& Buikstra, J. E. (1984). The relationship between cranial metric and non-metric traits in the rhesus macaques from Cayo Santiago. American Journal of Physical Anthropology, 64(3), 213-222. doi:10.1002/ajpa.133 0640303.

Rizk, O. T., Amugongo, S., Mahaney, M. C., \& Hlusko, L. J. (2008). The quantitative genetic analysis of primate dental variation: History of the approach and prospects for the future. In J. D. Irish \& G. C. Nelson (Eds.), Technique and application in dental anthropology. Cambridge: Cambridge University Press.

Roff, D. A. (1995). The estimation of genetic correlations from phenotypic correlations-A test of Cheverud's conjecture. Heredity, 74, 481-490. doi:10.1038/hdy.1995.68.

Roff, D. A. (1996). The evolution of genetic correlations: An analysis of patterns. Evolution, 50, 1392-1403. doi:10.2307/2410877.

Rogers, J., Mahaney, M. C., Witte, S. M., Nair, S., Newman, D., Wedel, S., et al. (2000). A genetic linkage map of the baboon (Papio hamadryas) genome based on human microsatellite polymorphisms. Genomics, 67, 237-247. doi:10.1006/geno. 2000.6245.

Roseman, C. C. (2004). Detecting interregionally diversifying natural selection on modern human cranial form by using matched molecular and morphometric data. Proceedings of the National Academy of Sciences of the United States of America, 101, 12824-12829. doi:10.1073/pnas.0402637101.

Salazar-Ciudad, I., \& Jernvall, J. (2002). A gene network model accounting for development and evolution of mammalian teeth. Proceedings of the National Academy of Sciences of the United States of America, 99, 8116-8120. doi:10.1073/pnas.13 2069499.

Schlosser, G., \& Wagner, G. P. (2004). Modularity in development and evolution. Chicago: University of Chicago Press.

Schluter, D. (2000). The ecology of adaptive radiation. New York: Oxford University Press.
Sherwood, R. J., Duren, D. L., Demerath, E. W., Czerwinski, S. A., Siervogel, R. M., \& Towne, B. (2008). Quantitative genetics of modern human cranial variation. Journal of Human Evolution, 54, 909-914. doi:10.1016/j.jhevol.2008.02.009.

Shubin, N. (2002). Origin of evolutionary novelty: Examples from limbs. Journal of Morphology, 252, 15-28. doi:10.1002/jmor. 10017.

Shubin, N., Tabin, C., \& Carroll, S. (1997). Fossils, genes, and the evolution of animal limbs. Nature, 388, 639-648. doi:10.1038/ 41710.

Steppan, S. J., Phillips, P. C., \& Houle, D. (2002). Copmarative quantitative genetics: Evolution of the $\mathrm{G}$ matrix. Trends in Ecology \& Evolution, 17(7), 320-327. doi:10.1016/S0169-5347 (02)02505-3.

Stern, D. L. (2000). Perspective: Evolutionary developmental biology and the problem of variation. Evolution, 54, 1079-1091.

Stock, D. W. (2001). The genetic basis of modularity in the development and evolution of the vertebrate dentition. Philosophical Transactions of the Royal Society of London, Series B: Biological Sciences, 356, 1633-1653. doi:10.1098/rstb.2001.0917.

Tucker, A., \& Sharpe, T. (2004). The cutting-edge of mammalian development; how the embryo makes teeth. Nature Reviews Genetics, 5, 499-508. doi:10.1038/nrg1380.

Van Valen, L. (1961). Growth fields in the dentition of Peromyscus. Evolution, 16, 272-273. doi:10.2307/2406276.

Wagner, G. P. (1996). Homologues, natural kinds and the evolution of modularity. American Zoologist, 36, 36-43.

Wagner, G. P., Pavlicev, M., \& Cheverud, J. M. (2007). The road to modularity. Nature Reviews Genetics, 8, 921-931. doi:10.1038/ $\operatorname{nrg} 2267$.

Wagner, G. P., \& Vargas, A. O. (2008). On the nature of thumbs. Genome Biology, 9, 213. doi:10.1186/gb-2008-9-3-213.

Weiss, K. M. (2005). The phenogenetic logic of life. Nature Reviews Genetics, 6, 36-45. doi:10.1038/nrg1502.

Weiss, K. M. (2008). All roads lead to... everywhere? Evolutionary Anthropology, 17, 88-92. doi:10.1002/evan.20156.

Weiss, K. M., Stock, D. W., \& Zhao, Z. (1998). Dynamic interactions and the evolutionary genetics of dental patterning. Critical Reviews in Oral Biology and Medicine, 9, 369-398.

Wolf, J. B., Leamy, L. J., Routman, E. J., \& Cheverud, J. M. (2005). Epistatic pleiotropy and the genetic architecture of covariation within early and late-developing skull trait complexes in mice. Genetics, 171, 683-694. doi:10.1534/genetics.104.038885. 